\title{
Evaluation of Steel Shear Walls Behavior with Sinusoidal and Trapezoidal Corrugated Plates
}

\author{
Emad Hosseinpour, ${ }^{1}$ Shahrizan Baharom, ${ }^{1}$ and Yasser Yadollahi ${ }^{2}$ \\ ${ }^{1}$ Department of Civil and Structural Engineering, Faculty of Engineering and Built Environment, Universiti Kebangsaan Malaysia, \\ 43600 Bandar Baru Bangi, Selangor, Malaysia \\ ${ }^{2}$ Department of Structural Engineering, Faculty of Civil Engineering, University of Shomal, Amol 84596, Iran
}

Correspondence should be addressed to Shahrizan Baharom; shah@eng.ukm.my

Received 5 January 2015; Accepted 8 March 2015

Academic Editor: Wei-Chau Xie

Copyright (C) 2015 Emad Hosseinpour et al. This is an open access article distributed under the Creative Commons Attribution License, which permits unrestricted use, distribution, and reproduction in any medium, provided the original work is properly cited.

\begin{abstract}
Reinforcement of structures aims to control the input energy of unnatural and natural forces. In the past four decades, steel shear walls are utilized in huge constructions in some seismic countries such as Japan, United States, and Canada to lessen the risk of destructive forces. The steel shear walls are divided into two types: unstiffened and stiffened. In the former, a series of plates (sinusoidal and trapezoidal corrugated) with light thickness are used that have the postbuckling field property under overall buckling. In the latter, steel profile belt series are employed as stiffeners with different arrangement: horizontal, vertical, or diagonal in one side or both sides of wall. In the unstiffened walls, increasing the thickness causes an increase in the wall capacity under large forces in tall structures. In the stiffened walls, joining the stiffeners to the wall is costly and time consuming. The ANSYS software was used to analyze the different models of unstiffened one-story steel walls with sinusoidal and trapezoidal corrugated plates under lateral load. The obtained results demonstrated that, in the walls with the same dimensions, the trapezoidal corrugated plates showed higher ductility and ultimate bearing compared to the sinusoidal corrugated plates.
\end{abstract}

\section{Introduction}

Steel shear walls are used in construction of skyscrapers in most developed seismic countries such as United States, Japan, and Canada in recent four decades. These walls have great advantages over similar structures such as reinforced concrete shear wall and steel braces. Steel shear walls have several benefits, including high ultimate bearing, perfect plasticity, high energy absorption capacity, appropriate stiffness, low structural weight, low construction costs, high quality, and high speed construction. The overall structures of steel shear walls consist of boundary members such as beam and columns, and infill steel plates in the spaces between them. Steel shear wall is constructed in two types: unstiffened and stiffened. In the former, unstiffened walls, a series of flat plates with light thickness that their postbuckling field is used in overall buckling. In the latter, belt series or steel profiles are utilized as stiffeners with different arrangements of horizontal, vertical, and diagonal in one side or both sides of wall until the energy dissipation, stiffness, and ultimate bearing are increased. Use of the first type is completely uneconomic because for improving the hysteresis curve of the mentioned walls, it is necessary to increase the thickness of the steel plate until the plate does not buckle before yielding of it; this increase in thickness makes it uneconomic. On the other hand, the second type of steel shear walls that strengthens the plate by a series of stiffeners is economical and quite effective. When stiffened steel shear walls are used, the hysteresis curves turn to spindle-shape from S-shape, which increases the hysteresis curve area. However, due to welding operations, this method demands high executive cost for joining the stiffeners to wall.

An appropriate alternative is using corrugated steel plates that demand a lower cost and also enjoy ductility. In addition, in the corrugated plates, the corrugate function is similar to that of stiffeners, and also these plates have appropriate stiffness. Performance of steel shear walls is similar to plate girder; as can be seen in Figure 1, plates, columns, and beams 


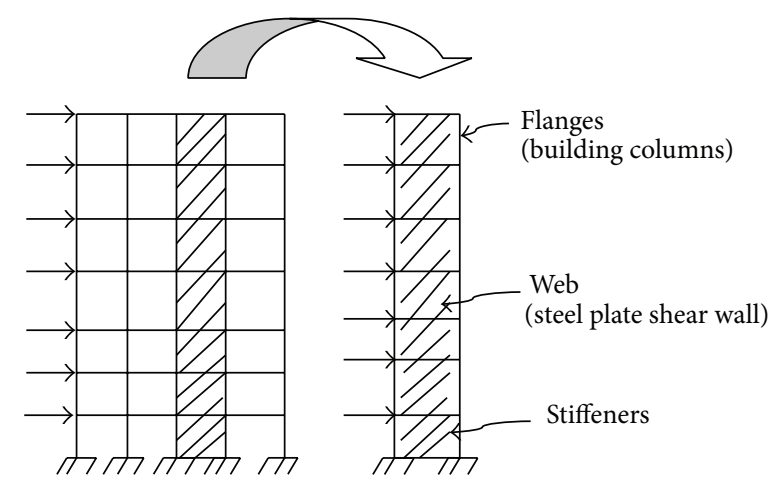

FIGURE 1: Steel plate shear wall and plate girder analogy [1].

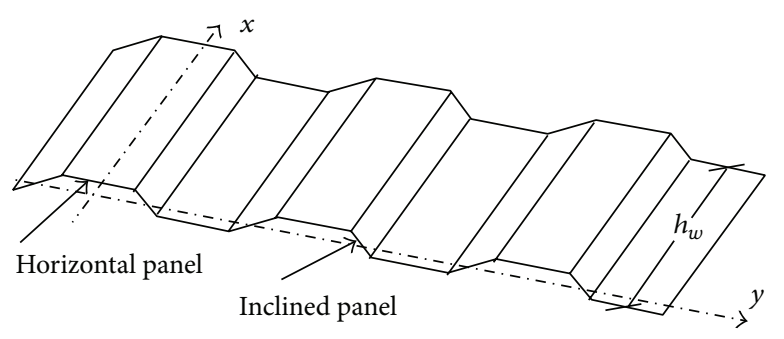

$c$

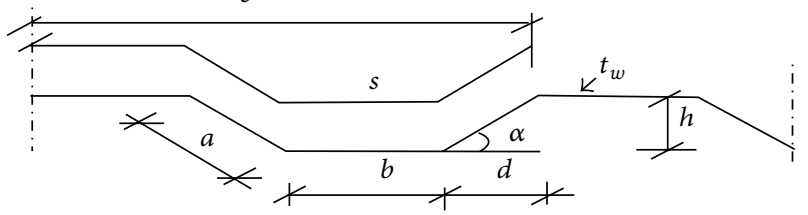

FIGURE 2: Geometric properties of trapezoidal corrugated plate [11, 12].

of steel shear walls are the same as webs, flanges, and stiffeners of plate girder, respectively $[1,2]$.

A great deal of research has been done on stiffened and unstiffened steel shear walls and trapezoidal web profile sections (see Formisano, 2006; Denan et al., 2010; De Matteis et al., 2008; Stojadinovic; and Tipping, 2008), and several theoretical works have been proposed [3-7].

Investigations on plate girder with corrugated steel plate have been done on laboratory activities of Wang (2003), Chosa et al. (2006), and Irizarry (2009) [8-10]. According to experimental activities and the cost of these types of studies, the investigation was limited to negligible component of these systems. Therefore, different components of corrugated plate such as thickness effect, wave's height, wave's lengths, stiffness of the boundary elements, and the effect of opening on the wall behavior have been neglected.

\section{Failure Modes of Corrugated Plates}

Geometric properties of trapezoidal and sinusoidal corrugated plate are shown in Figures 2 and 3.

Mainly, the infill plates provide and control the shear capacity of frame by their buckling or through failure. Pure shear stress is only significant stress in these structural

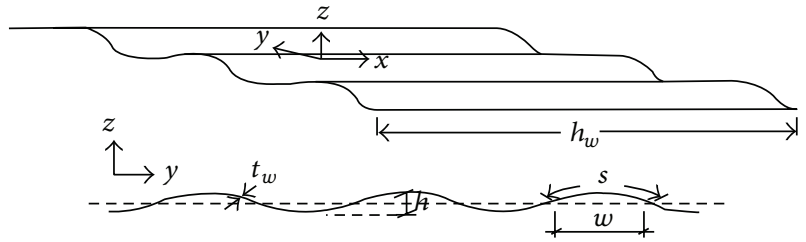

FIGURE 3: Geometric properties of sinusoidal corrugated plate.

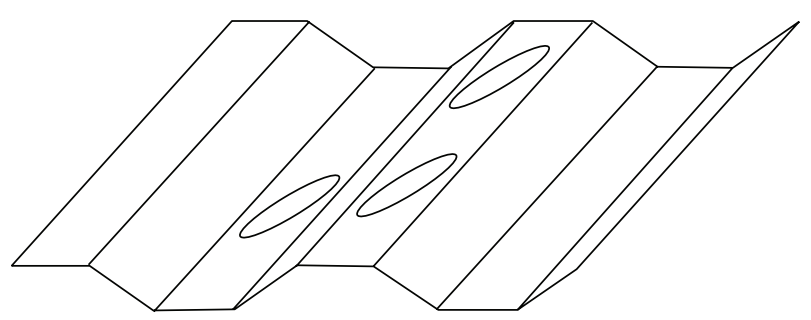

FIGURE 4: The local buckling form in corrugates of plate.

members. In corrugated plates, the yield shear stress can be determined by the following:

$$
\boldsymbol{\tau}_{y}=\frac{F_{y}}{\sqrt{3}}
$$

where $F_{y}$ signifies the yielding strength of steel [11-13].

There are two types of buckling control of the corrugated plates: overall buckling and local buckling. The local buckling mode of corrugated plates is formed in flat panels of trapezoidal corrugated plates and along the horizontal edge according to Figure 4. In this span, corrugated plates are connected to their short edges of column flange. In these conditions, the local buckling studied in isotropic plates and elastic critical shear stress for the local buckling mode is defined by (2) in trapezoidal and (3) in sinusoidal plates $[11,12,14-16]$ :

$$
\begin{aligned}
\boldsymbol{\tau}_{\mathrm{cr}, l} & =k_{s} \frac{\pi^{2} \cdot E}{12\left(1-v^{2}\right)} \cdot\left(\frac{t_{w}}{b}\right)^{2} \\
\boldsymbol{\tau}_{\mathrm{cr}, l} & =k_{s} \frac{\pi^{2} \cdot E}{12\left(1-v^{2}\right)} \cdot \frac{2 t_{w}}{s}
\end{aligned}
$$

where $t_{w}$ is the corrugated plates' thickness, $b$ denotes the length of wave in trapezoidal corrugated plate in which the local buckling occurs, $s$ signifies the actual length of corrugate in plate with sinusoidal corrugated plate, $E$ represents modulus of elasticity, $\boldsymbol{v}$ stands for Poisson ratio of steel, and $k_{s}$ is shear buckling coefficient in the local buckling mode and its value is dependent on boundary conditions and the panel's aspect ratio $\left(b / h_{w}\right)$ where $h_{w}$ denotes the height of the plate.

According to Figure 5, the global buckling is formed with global diagonal buckling of multiwaves in corrugated plate. In this case, the critical shear stress is estimated with respect to corrugated plate as an orthotropic plate [17-19].

Elgaaly in his laboratory research on the Trapezoidal corrugated plates showed that if the waves of corrugated plate are large, the local buckling can be formed in the horizontal 


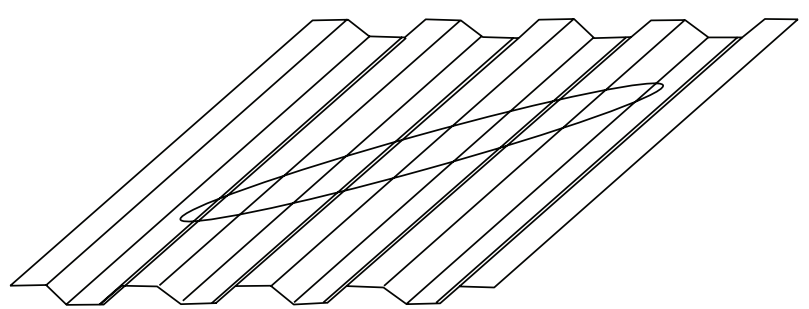

FIGURE 5: Global buckling on trapezoidal corrugated plate.

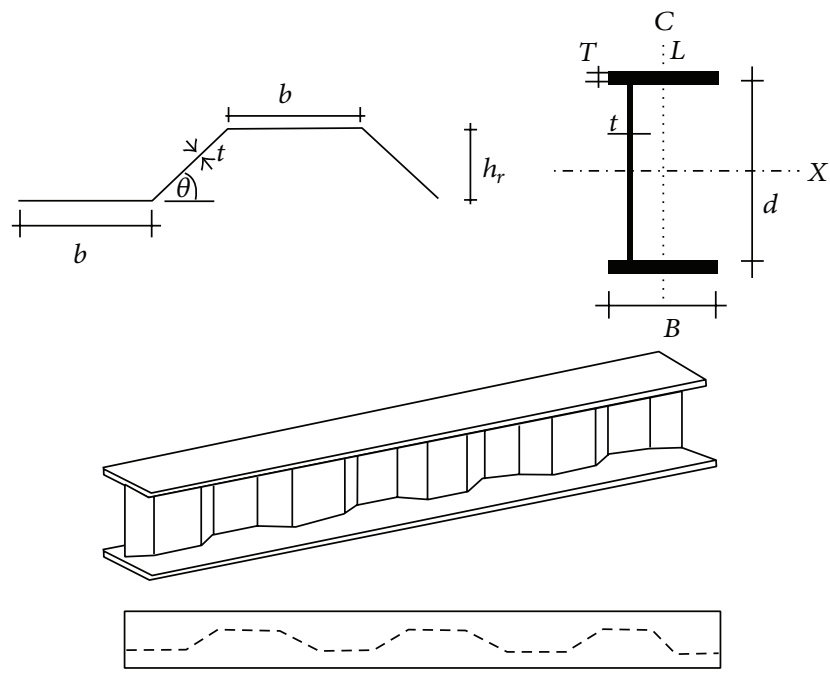

FIGURE 6: Geometric properties of TS600-3 specimen [22, 23].

TABLE 1: Dimensions of TS600-3 plate girder (mm).

\begin{tabular}{ccccccc}
\hline$\theta$ & $B$ & $T$ & $d$ & $\mathrm{hr}$ & $t$ & $b$ \\
\hline 45 & 200 & 15 & 600 & 80 & 3 & 170 \\
\hline
\end{tabular}

portion of each corrugated plate, and if the lengths of waves are small, then the global buckling can be formed in plate without controlling [20].

The above equations were used in plate girder with trapezoidal and sinusoidal waves. Therefore, this paper makes a comparison between the trapezoidal corrugated plates and the sinusoidal plates using Finite element method.

\section{Modeling and the Validation of Simulation}

This section explains the assumptions on finite element (FE) modeling and evaluates the methodology selected for validation of simulation in the software modeling.

3.1. Assumptions and the Validation of Modeling. In this part of study, the plate girder with trapezoidal web plate is investigated under monotonic loading. The geometric properties of plate girder on software are shown in Figure 6 and Table 1.

The steel material consumed in the model has elasticplastic curve of strain-stress with modulus of elasticity $200 \mathrm{Gpa}$, Poisson ratio of 0.3 , and yield strength of $355 \mathrm{Mpa}$.

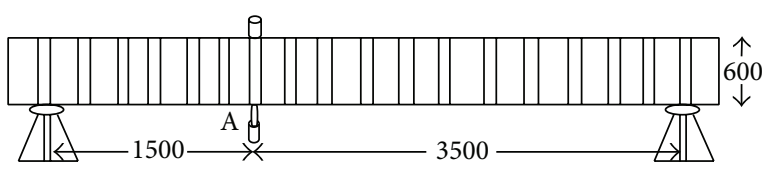

FIGURE 7: Loading one-span beam in location (A) (TS600-3-A) [21].

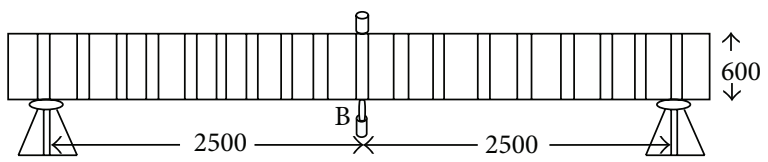

FIGURE 8: Loading one-span beam in location (B) (TS600-3-B) [21].

TABLE 2: Obtained result of experimental and ANSYS models.

\begin{tabular}{lcccc}
\hline \multicolumn{2}{c}{$\begin{array}{c}\text { Ultimate deflection } \\
(\mathrm{mm})\end{array}$} & \multicolumn{3}{c}{$\begin{array}{c}\text { Ultimate load } \\
(\mathrm{KN})\end{array}$} \\
Experimental & ANSYS & Experimental & ANSYS & Model \\
\hline 22.9 & 26.57 & 284.85 & 355.58 & TS600-3-A \\
20.5 & 19.27 & 285.45 & 264.26 & TS600-3-B \\
14.05 & 15.12 & 285.45 & 300.59 & TS600-3-C \\
\hline
\end{tabular}

The von misses criteria are used for evaluation of mode result because the steel material was applied. The force and displacement criteria are the conversation criteria. The element of shell 143 is used for flange, web, and stiffener of experimental plate girder modeling in ANSYS software. Figures 7, 8, 9, and 10 show the experimental activities of Usman (2001) on three plate girders used in one-span beam with simple supports that the monotonic load were applied on first onethird (A), mid one-third (B), and end one-third (C) of the beam span [21]. The arc-length method was used to solve the numerical models, and the size element meshing and time stepping were considered $50 \mathrm{~mm}$ and 0.001 , respectively, for good accuracy and conversation. The finite element modeling of these activities are shown in Figures 11, 12, and 13.

Regarding the results related to three-point loaded which are demonstrated in Table 2, the modeling in ANSYS software has more reasonable accuracy than experimental models. This represents the accuracy of modeling, chosen elements, and the assumptions. Minor differences in results of comparison presented in Figure 14 are due to the type of verification tools.

3.2. Numerical Modeling and Analyses of Steel Shear Wall. The numerical analyses were performed on one story and one span wall with $3000 \mathrm{~mm}$ width and $2600 \mathrm{~mm}$ height. The boundary member was IPB180 and IPE180 for columns and beam, respectively. The infill plate used in this wall was sinusoidal and trapezoidal corrugated plate that was connected to surrounding frame rigidity. The geometry and meshing configuration of these walls are shown in Figure 15. The walls were clamped to support the bottom of wall and the wall's frame was simply supported in order to prevent out of plane displacement that may occur due to concentration load that acts on top of beam to column connected location. 


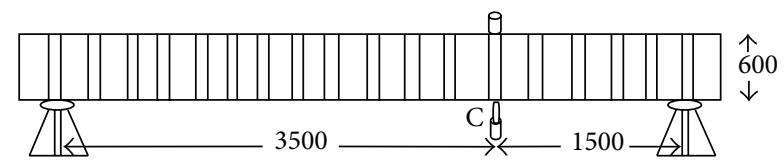

FIgURE 9: Loading one-span beam in location (C) (TS600-3-C) [21].

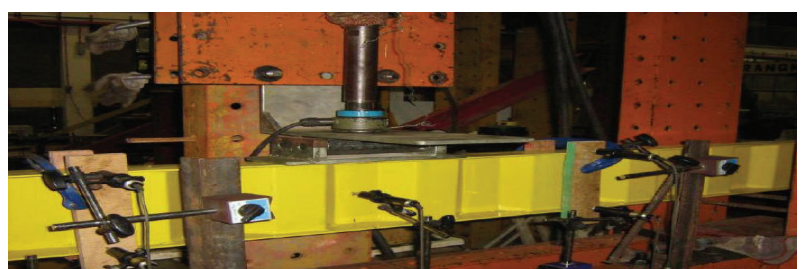

FIgURE 10: The testing rig and loading at mid span [21].
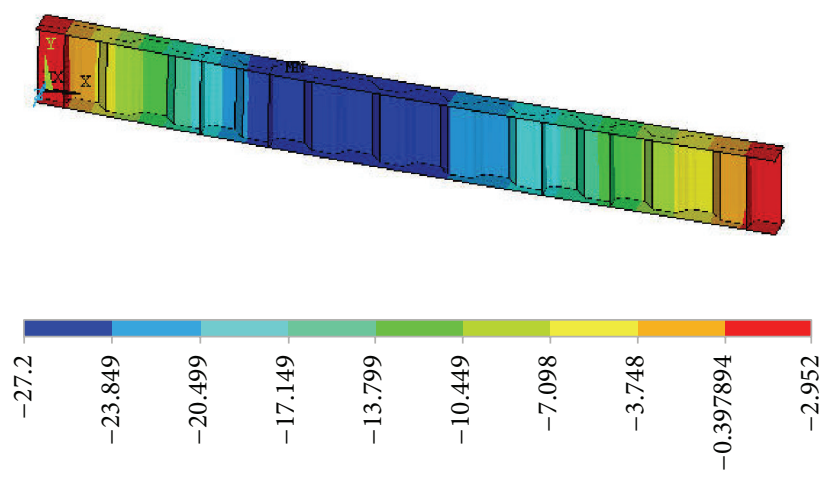

FIGURE 11: FE model of TS600-3-A.
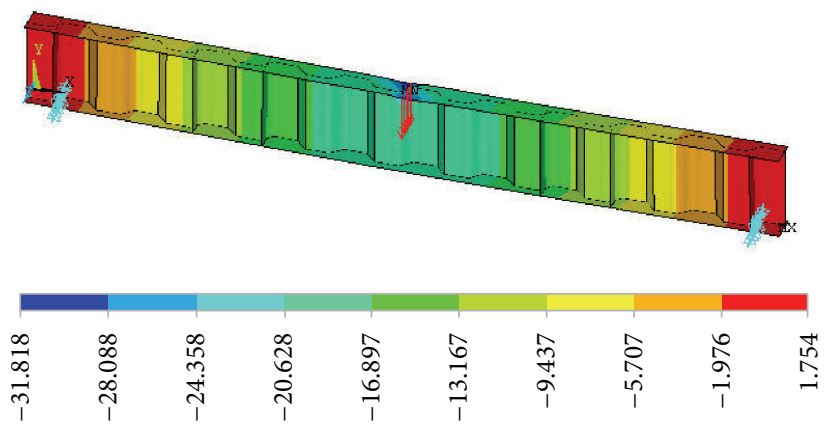

Figure 12: FE model of TS600-3-B.

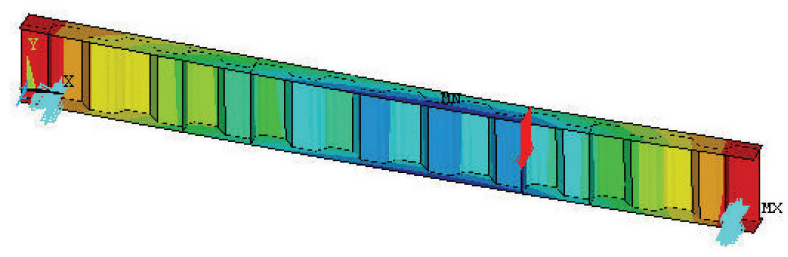

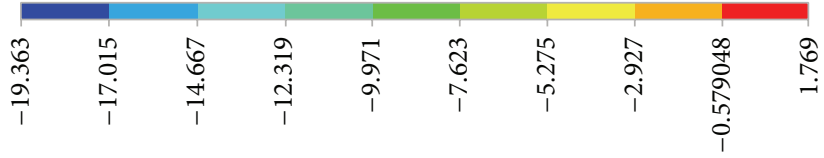

FIGURE 13: FE model of TS600-3-C.
TABLE 3: Geometrical dimensions of sinusoidal plate.

\begin{tabular}{lll}
\hline$h / 2 w$ & $h$ & $w$ \\
\hline 0.16 & 19 & 60
\end{tabular}

TABLE 4: Geometrical dimensions of trapezoidal plate.

\begin{tabular}{cccccc}
\hline$h / c$ & $\alpha$ & $d$ & $a$ & $h$ & $b$ \\
\hline 0.16 & 45 & 80 & 113 & 80 & 170 \\
\hline
\end{tabular}

TABLE 5: FE modeling results of trapezoidal corrugated plates.

\begin{tabular}{lccc}
\hline $\begin{array}{l}\text { Thickness } \\
(\mathrm{mm})\end{array}$ & $\begin{array}{c}\text { Load } \\
(\mathrm{KN})\end{array}$ & $\begin{array}{c}\text { Displacement } \\
(\mathrm{mm})\end{array}$ & $\begin{array}{c}\text { Stiffness } \\
(\mathrm{KN} / \mathrm{mm})\end{array}$ \\
\hline 1.5 & 628.55 & 15.8 & 95.59 \\
3 & 1114.95 & 49.45 & 134.38 \\
5 & 1386.55 & 78.17 & 167.51 \\
10 & 1525.95 & 88.37 & 218.45 \\
15 & 1745.32 & 115.19 & 238.36 \\
20 & 1825.45 & 110.07 & 272.52 \\
\hline
\end{tabular}

The load is applied on columns in uniform increase form. In these models, an elastic-plastic material model was assumed with yield strength value of $240 \mathrm{Mpa}$, modulus of elasticity of $200 \mathrm{Gpa}$, and Poisson ratio of 0.3 . Also the geometric nonlinearity was used due to large displacement.

\section{Evaluation of the Parametric Study Results}

In this part, the effect of some geometric properties such as thickness of plate, depth or wave height of plate, length of wave, corrugated density, and stiffness of beam and columns on corrugated steel walls were investigated. In the following paragraphs, the results of these parameters are presented in detail.

4.1. The Thickness Effect of the Corrugated Plate. The thicknesses that are considered for study of thickness effect in sinusoidal and trapezoidal corrugated plate are 1.5, 3, 5, 10, 15 , and $20 \mathrm{~mm}$. In these models, the columns and beam are considered the IPB180 and IPE 180, respectively. The geometric properties of applying plate are demonstrated in Tables 3 and 4, where $w$ signifies the horizontal projection of one wave on sinusoidal plate, $b$ is the horizontal panel width in trapezoidal plate, $h$ denotes the corrugation magnitude, $t_{w}$ presents the plate thickness, $s$ is the unfolded length of one corrugation in sinusoidal plate, $a$ represents the inclined panel width in trapezoidal plated that is the horizontal projection of the inclined panel width, $c$ stands for the horizontal projection of one wave on trapezoidal plate, $a$ is the corrugation angle in trapezoidal plate, and $h / 2 w$ and $h / c$ coefficients are the corrugation density in corrugated plates.

Tables 5 and 6 demonstrate the finite element modeling results of two different types of corrugated plate base on different thickness.

According to the results shown in Figure 16 for sinusoidal and trapezoidal corrugated plates with six different 

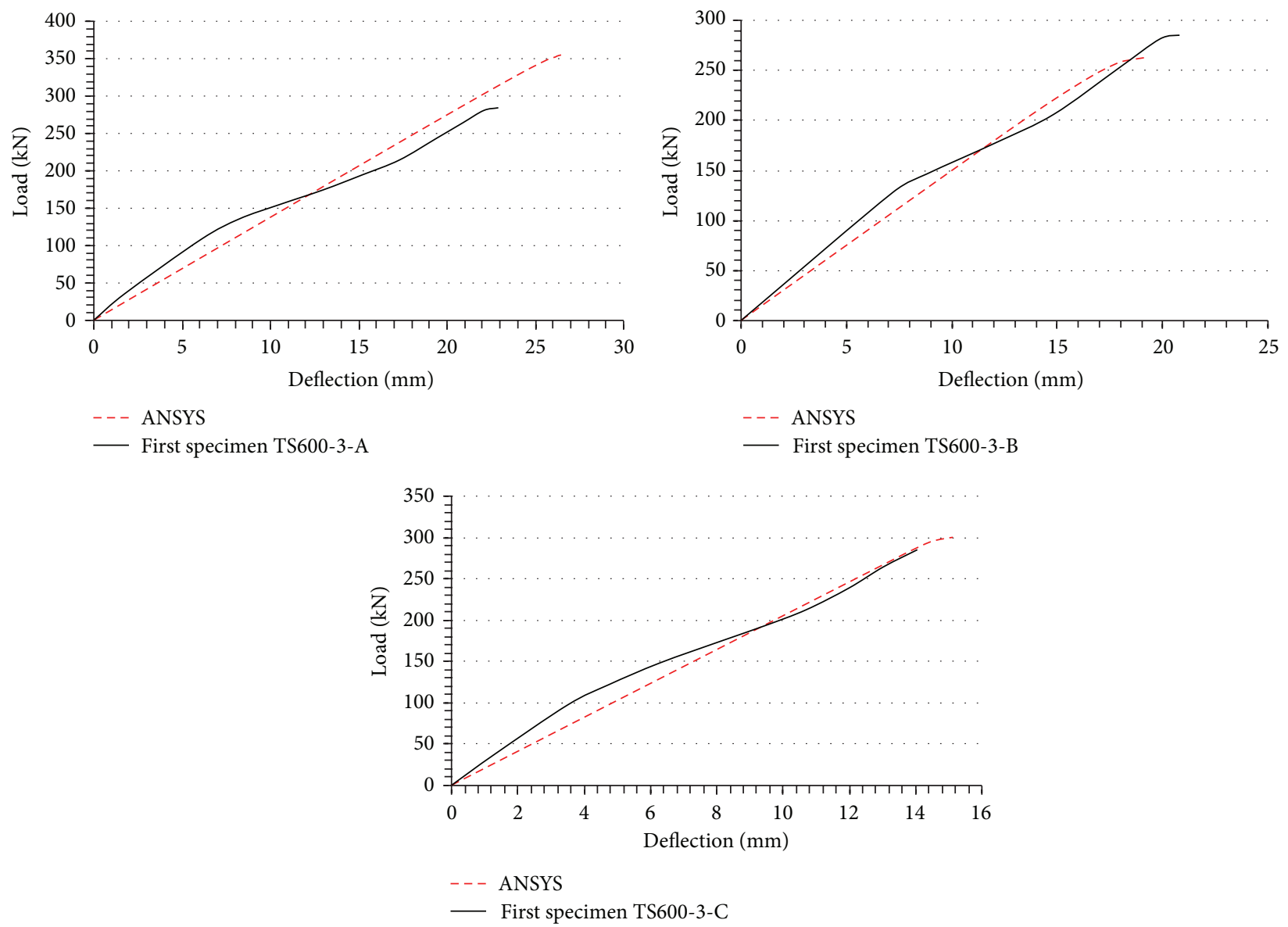

FIGURE 14: Load-deflection curve of experimental and ANSYS models of TS600-3.

TABLE 6: FE modeling results of sinusoidal corrugated plates.

\begin{tabular}{lccc}
\hline $\begin{array}{l}\text { Thickness } \\
(\mathrm{mm})\end{array}$ & $\begin{array}{c}\text { Load } \\
(\mathrm{KN})\end{array}$ & $\begin{array}{c}\text { Displacement } \\
(\mathrm{mm})\end{array}$ & $\begin{array}{c}\text { Stiffness } \\
(\mathrm{KN} / \mathrm{mm})\end{array}$ \\
\hline 1.5 & 200.5 & 2.1 & 89.61 \\
3 & 517.35 & 22.51 & 130.16 \\
5 & 780.77 & 20.83 & 172.13 \\
10 & 1108.65 & 26.47 & 255.62 \\
15 & 1500.12 & 38.16 & 326.23 \\
20 & 2000.25 & 56.69 & 385.21 \\
\hline
\end{tabular}

thicknesses, the ultimate bearing capacity is increased with increasing the thickness. Additionally, with an increase in the plate thickness, out of plane deformation of the wall accelerates the formation to plastic hinge around the beam to column connection. It is necessary to explain that although the result of increasing of thickness on ultimate bearing was predictable, it is a reason for accuracy of software performance.

With compression of the results shown in loaddisplacement and energy-displacement curves in sinusoidal and trapezoidal steel corrugated plates and with noting that corrugation density is equal to 0.16 for both plates, it is shown that corrugated plate with trapezoidal wave has more ductility than sinusoidal wave. Then, according to the obtained results, it has more energy dissipation. In both walls, with a low thickness, the trapezoidal plate has better performance in ultimate bearing and energy dissipation compared to the sinusoidal plate; however, in high thickness of plate, the sinusoidal plate has more ultimate bearing than trapezoidal plate; furthermore, in this condition, the sinusoidal plates are yielded under buckling, while the trapezoidal plate is yielded under the plastic hinge formation on beam.

The stiffness performance of one story steel shear wall system with sinusoidal and trapezoidal corrugated plate under in-plane load is shown Figure 17, showing that with increasing of the plate thickness, the stiffness is increased in elastic and postelastic range. Also the stiffness of all models is gradually decreased without any abrupt change even at the onset of shear buckling. Moreover, with increasing of the plate thickness, the sinusoidal corrugation plate has more stiffness than trapezoidal corrugated plates. Moreover, the stiffness drop slope is more in trapezoidal plates.

4.2. The Stiffness Effect of the Boundary Members. To study of the boundary members such as beam and column in corrugated steel shear wall, the six different sections of IPB for column are used in sinusoidal corrugated plate, where 


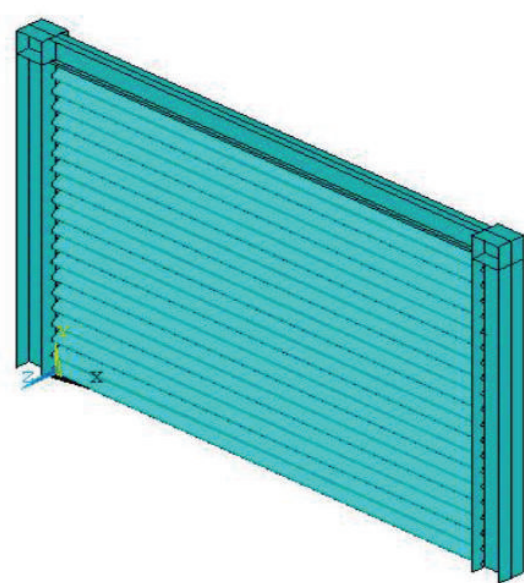

(a)

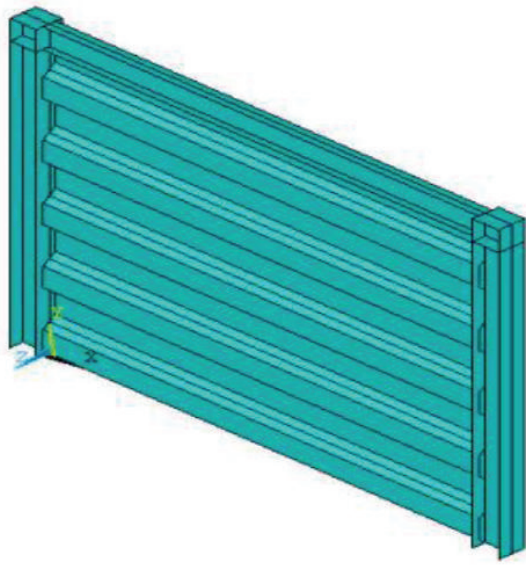

(b)

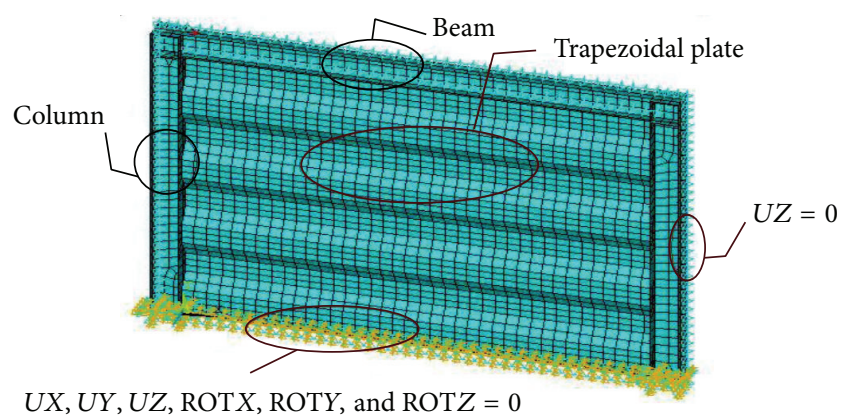

FIGURE 15: The mesh configuration of corrugated steel shear wall with (a) sinusoidal and (b) trapezoidal waves.

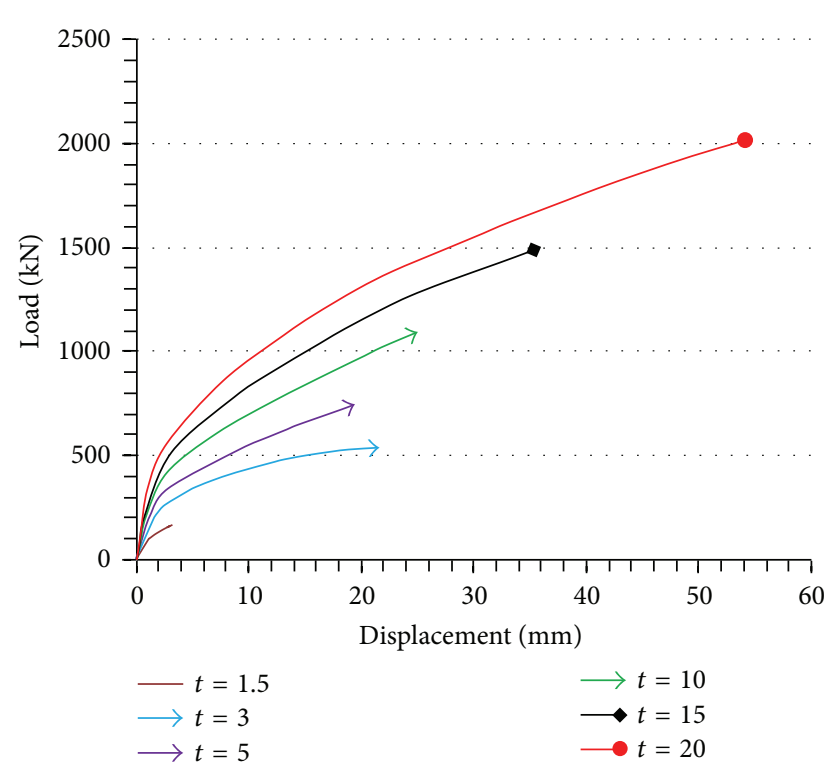

(a)

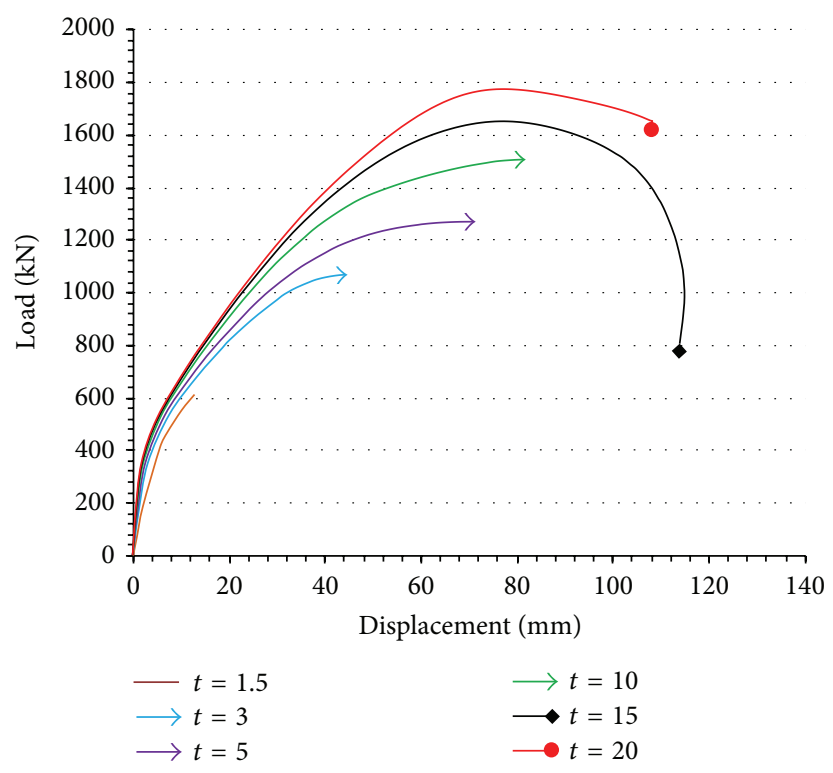

(b)

FIGURE 16: Load-displacement curves of (a) sinusoidal and (b) trapezoidal corrugated plates with different thicknesses. 


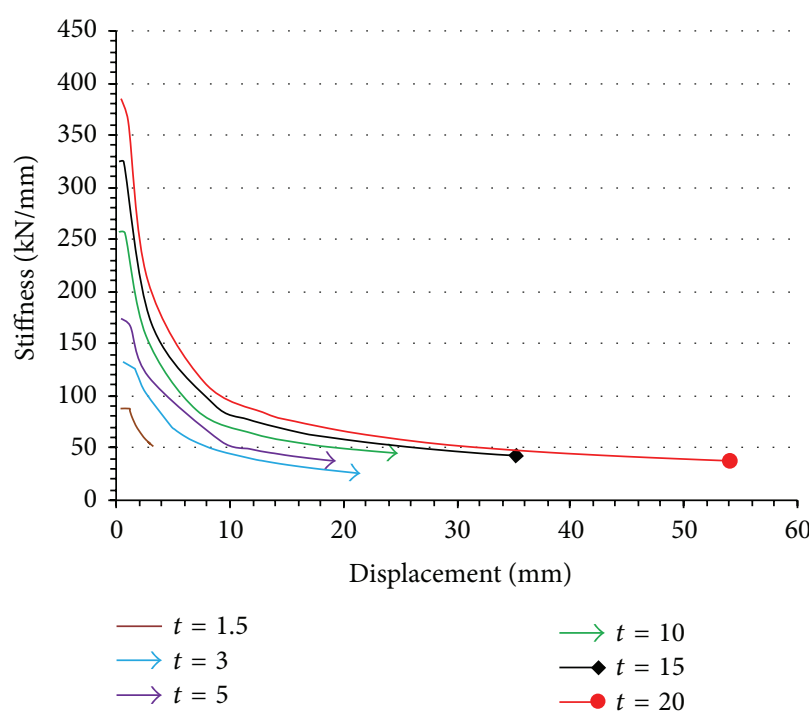

(a)

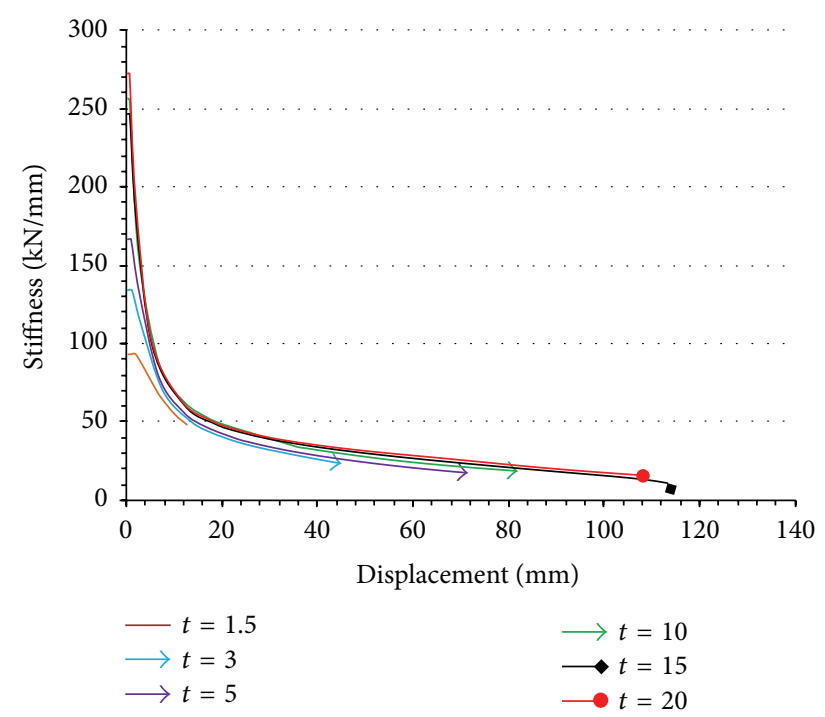

(b)

Figure 17: Performance of stiffness in (a) sinusoidal and (b) trapezoidal corrugated plates with different thicknesses.

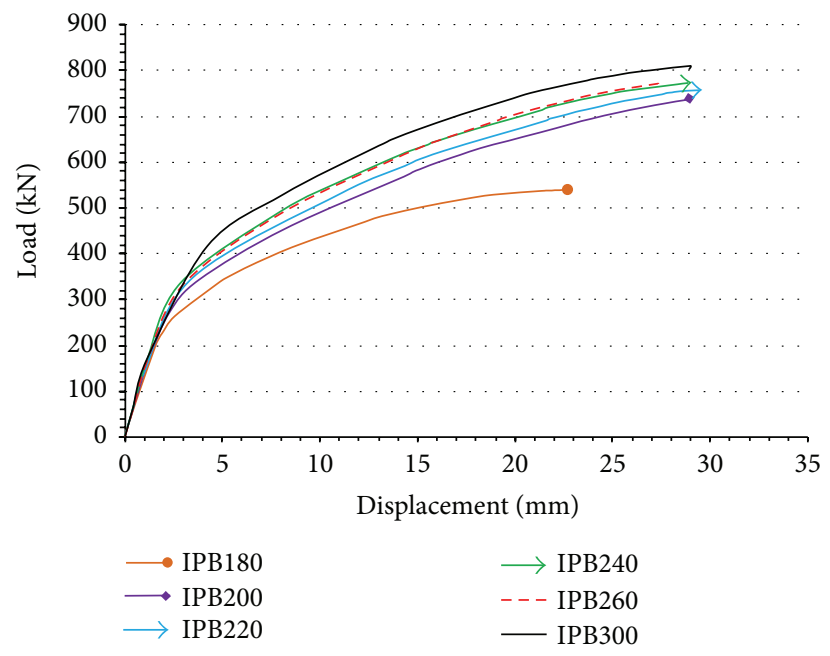

(a)

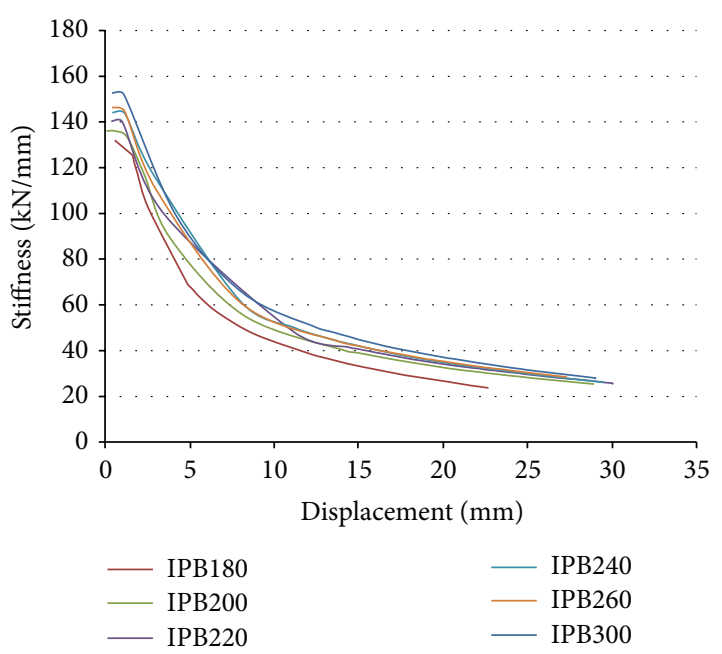

(b)

FIGURE 18: Performance of (a) load and (b) stiffness of sinusoidal corrugated plates with different columns.

the length of wave is $60 \mathrm{~mm}$, the height of wave is $19 \mathrm{~mm}$, and thickness of plate is $3 \mathrm{~mm}$. The columns studied in this section consist of IPB200, 220, 240, 260, and 300, and unique section of IPE180 for beams are used in these six models. In these models, with an increase in the section area of column, the ultimate bearing increases due to increasing of stiffness (see Figure 18). However, the energy dissipation does not have any determine process. As mentioned before, with increasing the column section area, the stiffness of system has been increased about 3 to 15.6 percent.

The beam sections investigated in this paper are IPE $180,200,220,240,270$, and 300 , and the column section is selected IPB180. According to Figure 19, with increasing the beam section, the ultimate bearing and stiffness of frame are increased. With an increase in the beam section, the stiffness performance is increased about 3 to 14.3 percent.

4.3. Corrugation Depth Effect in Corrugated Plates. The corrugation depth is one of parameters that increased lateral stiffness of corrugated plates. In this part, the effect of corrugation depth is studied on steel shear wall behavior with sinusoidal and trapezoidal corrugation. To examine the corrugation depth effect on sinusoidal corrugated plates, six specimens with different height of 19,30,40,50, 56, and $60 \mathrm{~mm}$ are used. The geometric characteristics of these plates are shown in Table 7.

The results of these specimens under in-plane load are shown in Figure 20. These results demonstrate that with 


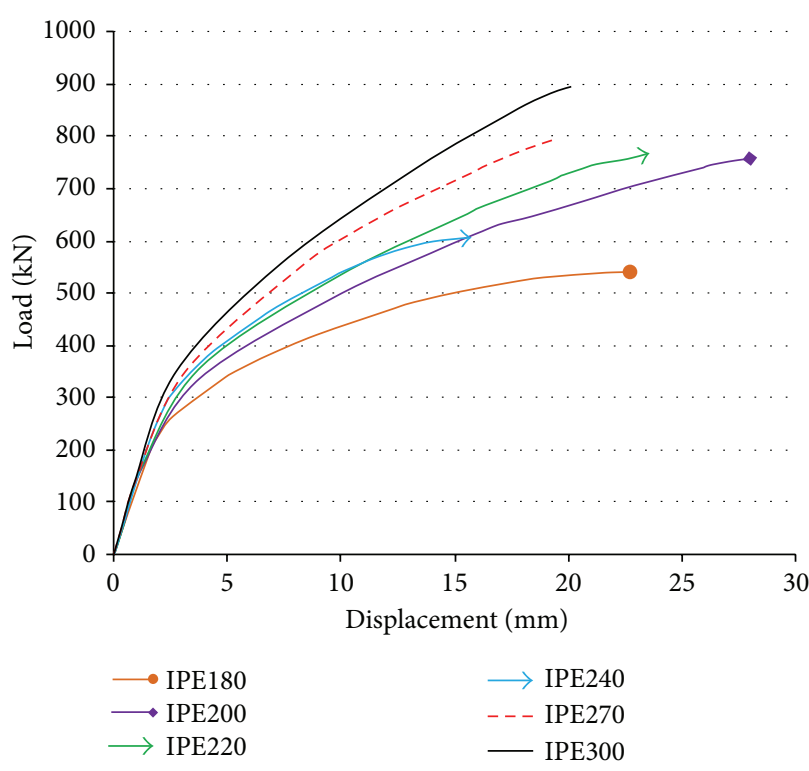

(a)

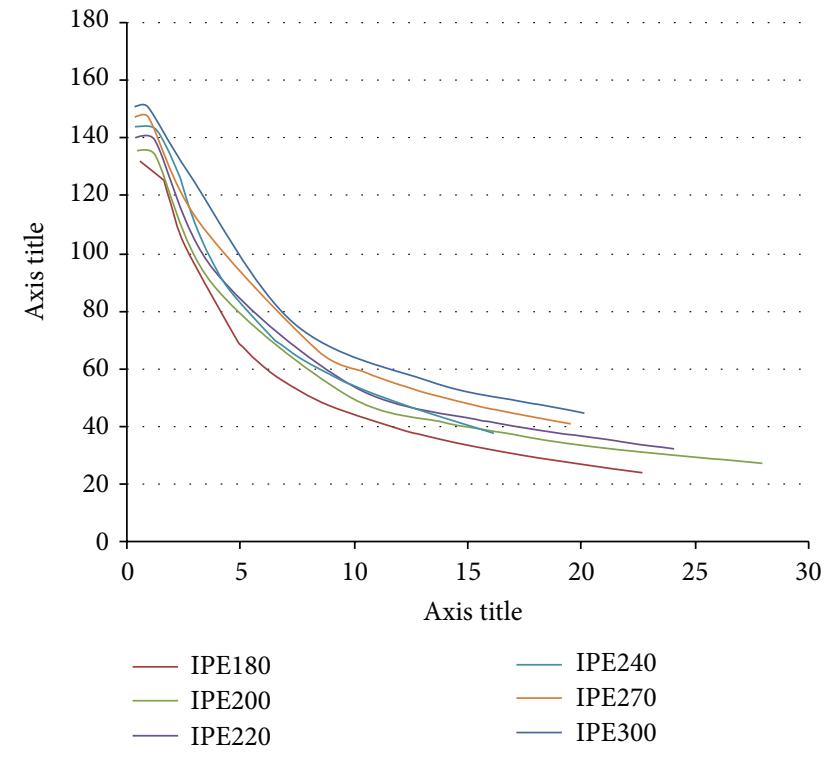

(b)

Figure 19: Performance of (a) load and (b) stiffness of sinusoidal corrugated plates with different beams.

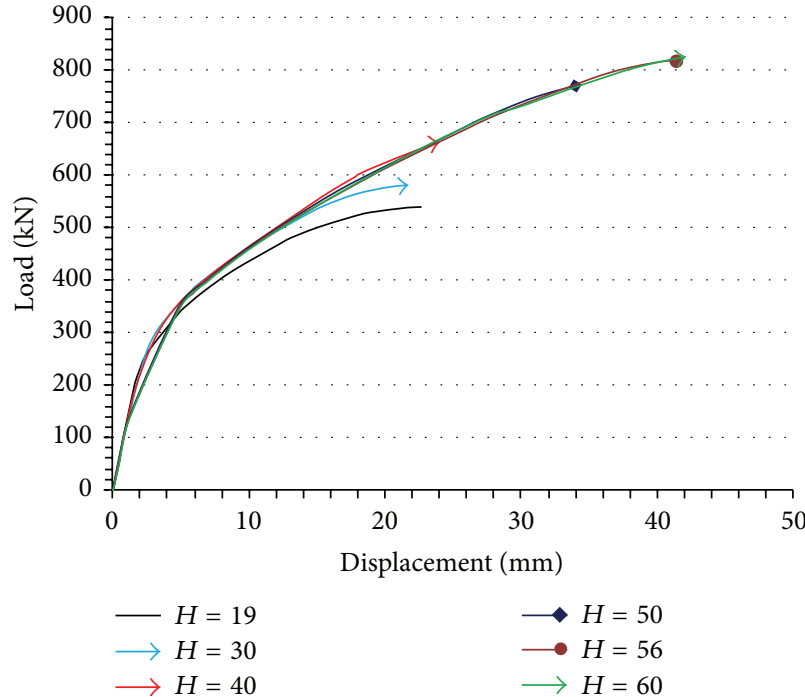

(a)

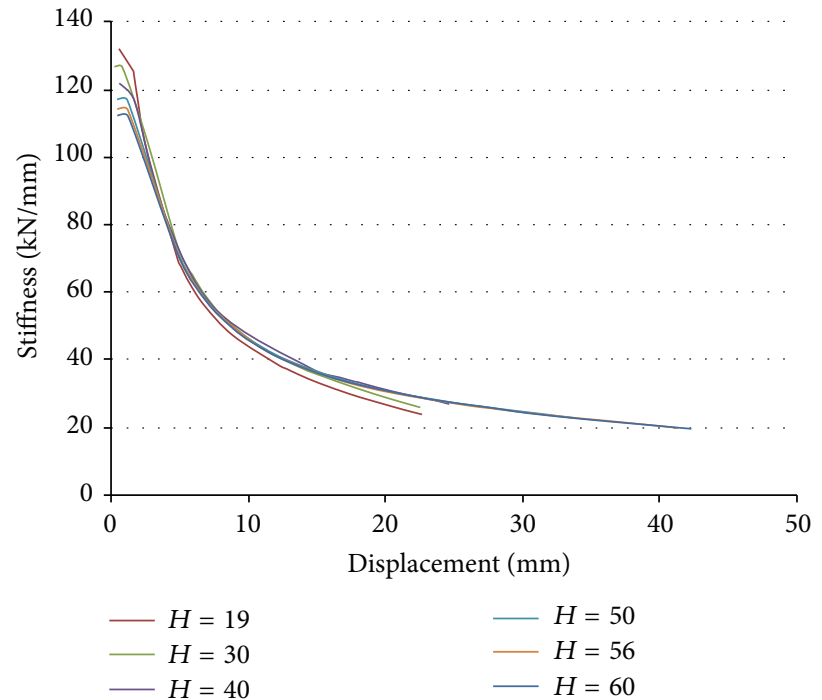

(b)

Figure 20: Performance of (a) load and (b) stiffness of sinusoidal corrugated plates with different corrugation depths.

TABLE 7: Geometrical characteristics of sinusoidal plates with different corrugation depths $(\mathrm{mm})$.

\begin{tabular}{lcc}
\hline$h$ & $t_{w}$ & $w$ \\
\hline $19,30,40,50,56,60$ & 3 & 60 \\
\hline
\end{tabular}

increasing of the corrugation depth, the ultimate bearing in sinusoidal plate and ductility significantly increase. The most important obtained result is that with increasing of the corrugation depth, the stiffness value decreased 4.2 to 17.6 percent.

Figure 21 shows that the ductility, energy dissipation, and ultimate bearing are increased with increasing the corrugation depth or corrugation density coefficient.

To investigate the effect of corrugation depth on the trapezoidal corrugated plates, five specimens whose characteristics are shown in Table 8 are used.

According to Figure 22, increase of corrugated height has insignificant effect on ultimate bearing and ductility. In addition, the stiffness performance of wall has been uniform. 


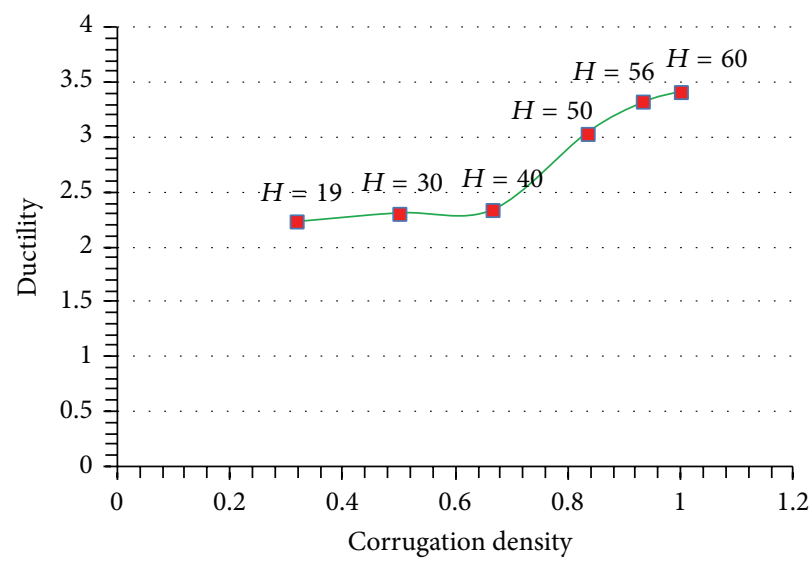

(a)

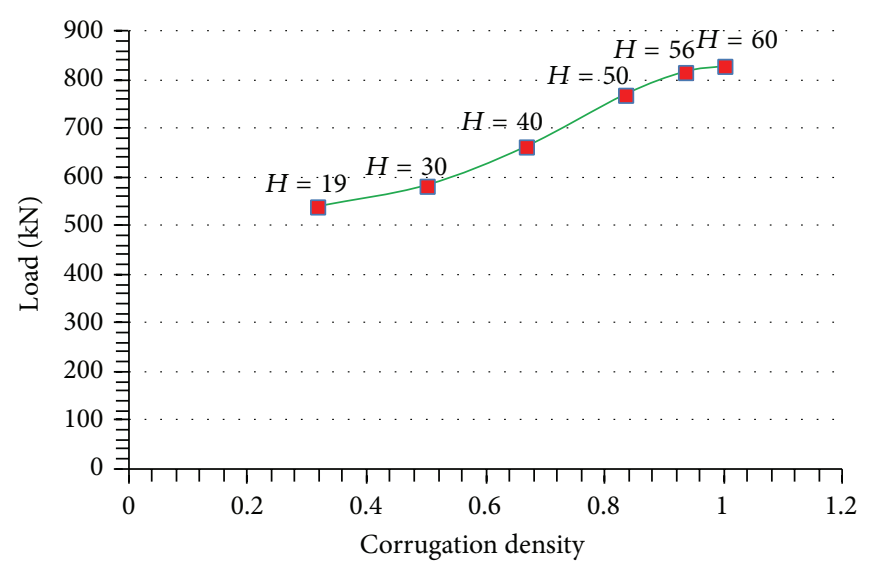

(b)

FIGURE 21: Corrugation density effect of sinusoidal corrugated plate on (a) ductility and (b) ultimate bearing.

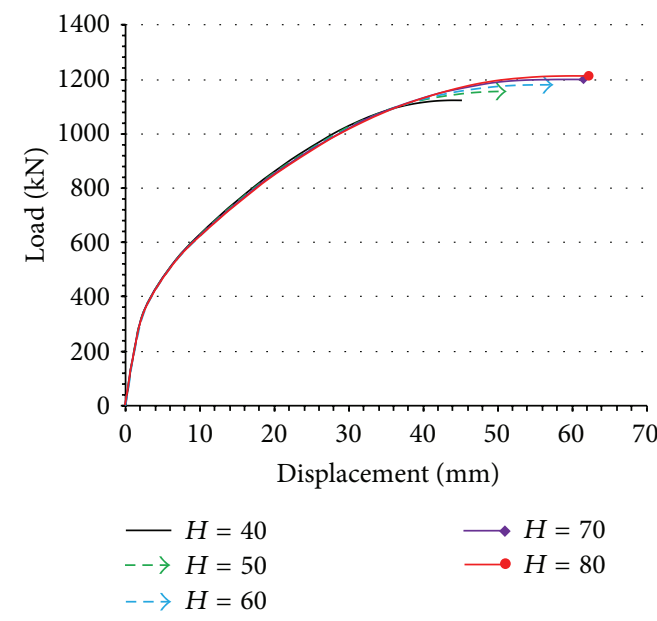

(a)

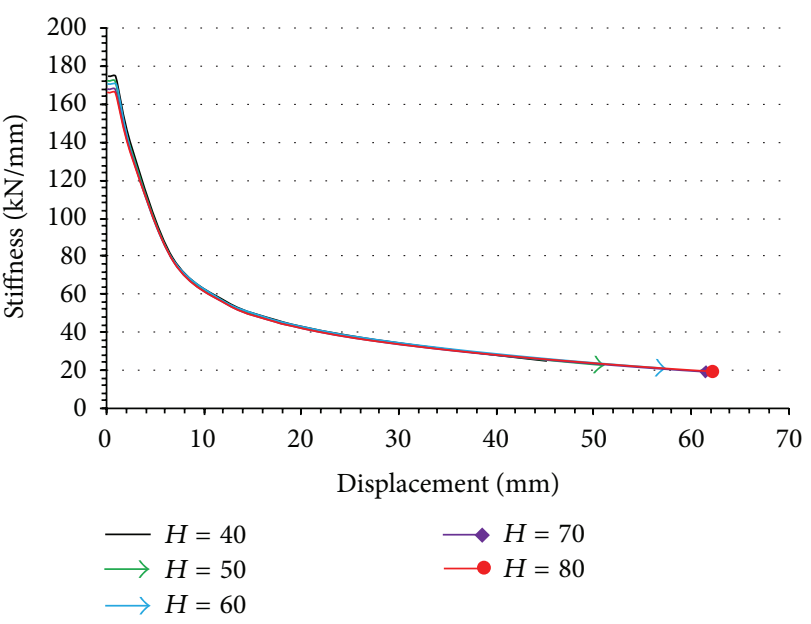

(b)

FIGURE 22: Performance of (a) load and (b) stiffness of trapezoidal corrugated plates with different corrugation depths.

TABLE 8: Geometrical characteristic of trapezoidal plates with different corrugation depths $(\mathrm{mm})$.

\begin{tabular}{lcccc}
\hline$D$ & $a$ & $t_{w}$ & $h$ & $b$ \\
\hline $40,50,60,70,80$ & 113 & 3 & 80 & 170 \\
\hline
\end{tabular}

4.4. The Corrugation Length Effect of Infill Corrugated Plates. In this part, the seven specimens sinusoidal and four specimens trapezoidal corrugated plates are for studying the corrugation length. The geometric characteristic of these models is shown in Tables 9 and 10 where $L$ signifies the corrugation length of sinusoidal plate equal to $w$ and equal to $d+b$ in trapezoidal corrugated plates.

According to Figure 23, the ultimate bearing of wall decreased with increasing of the corrugation length, and the walls lose their bearing due to global buckling failure. According to the stiffness performance of sinusoidal corrugated plate, it is shown that the initial stiffness has not changed due
TABLE 9: Geometrical characteristic of sinusoidal plates with different corrugation lengths ( $\mathrm{mm})$.

\begin{tabular}{lcc}
\hline$h$ & $t_{w}$ & $L=l$ \\
\hline 19 & 3 & $60,8,100,120,140,160,180$ \\
\hline
\end{tabular}

TABLE 10: Geometrical characteristic of trapezoidal plates with different corrugation lengths ( $\mathrm{mm})$.

\begin{tabular}{lcc}
\hline$h$ & $t_{w}$ & $L$ \\
\hline 80 & 3 & $130,180,250,280$ \\
\hline
\end{tabular}

to increasing of the corrugation length, and the ductility of wall has changed particularly.

Figure 24 shows that ultimate bearing and ductility have decreased with increasing of the corrugation length. Furthermore, it is shown that the performance of stiffness has increased with increasing the corrugation length of trapezoidal corrugated plate, but the losing stiffness process 


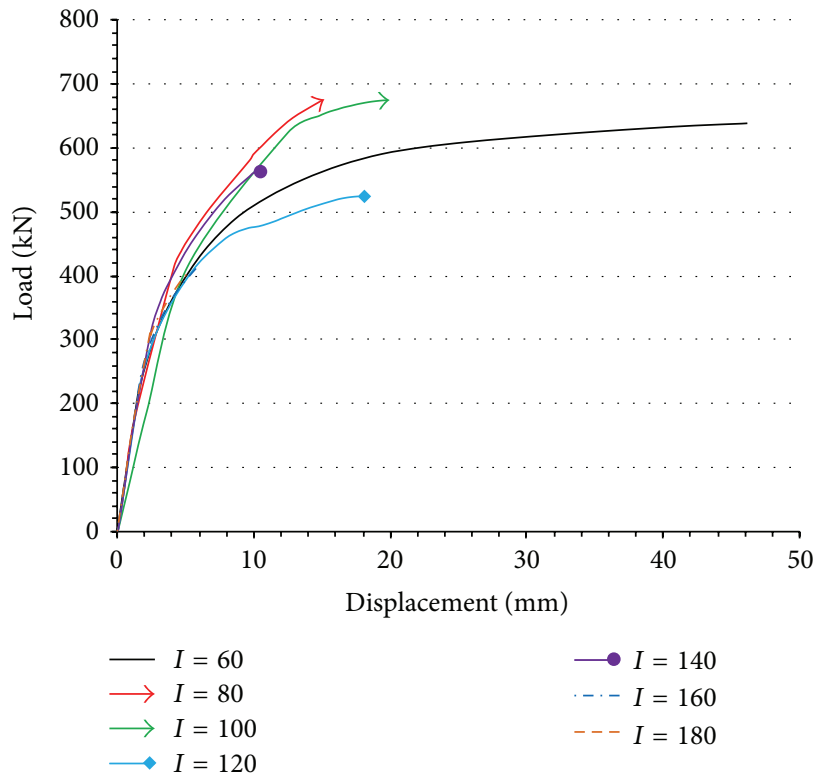

(a)

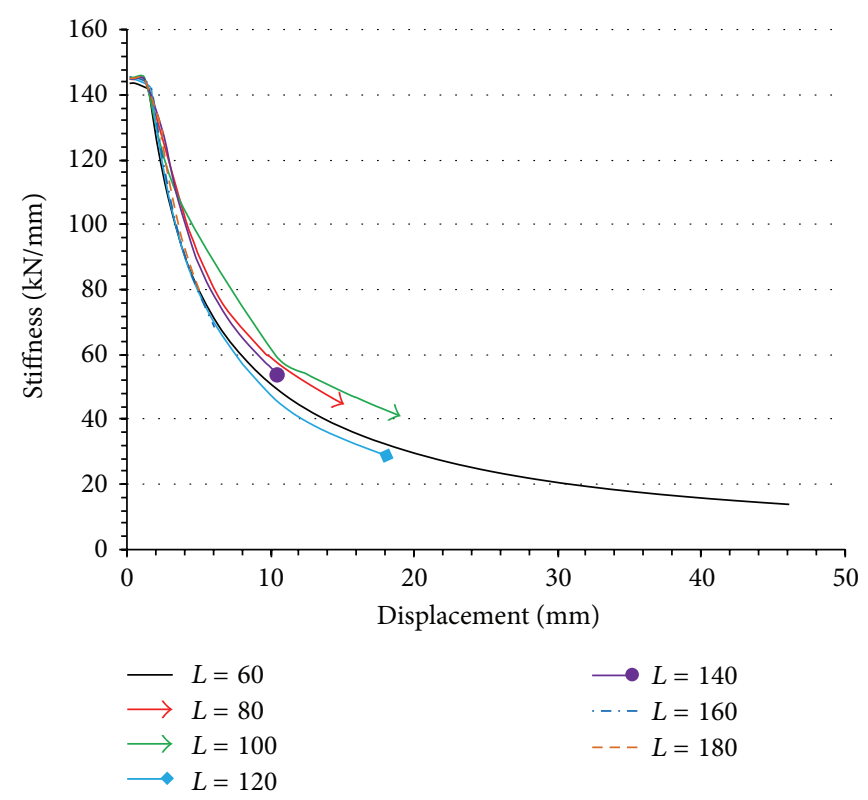

(b)

FIGURE 23: Performance of (a) load and (b) stiffness of sinusoidal corrugated plates with different corrugation lengths.

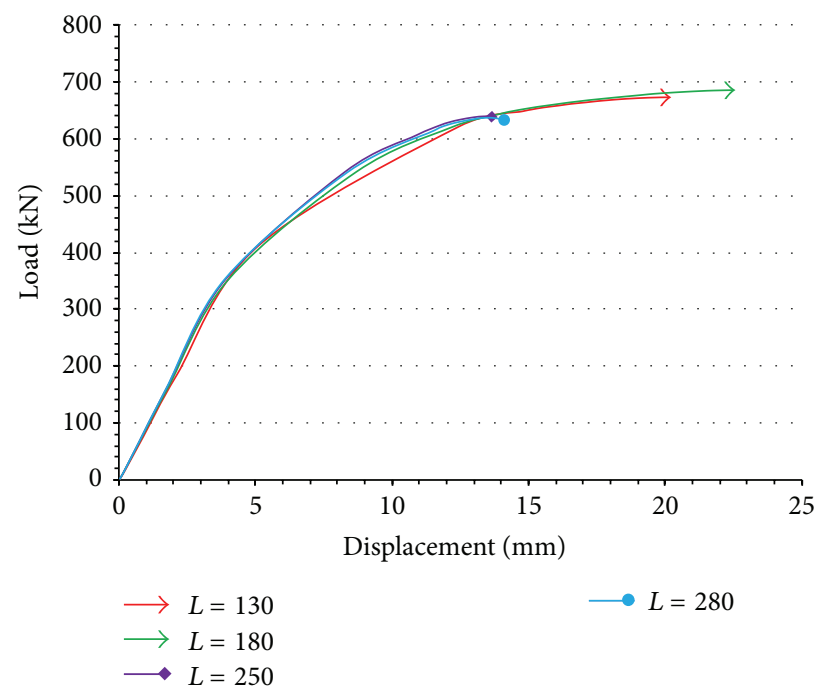

(a)

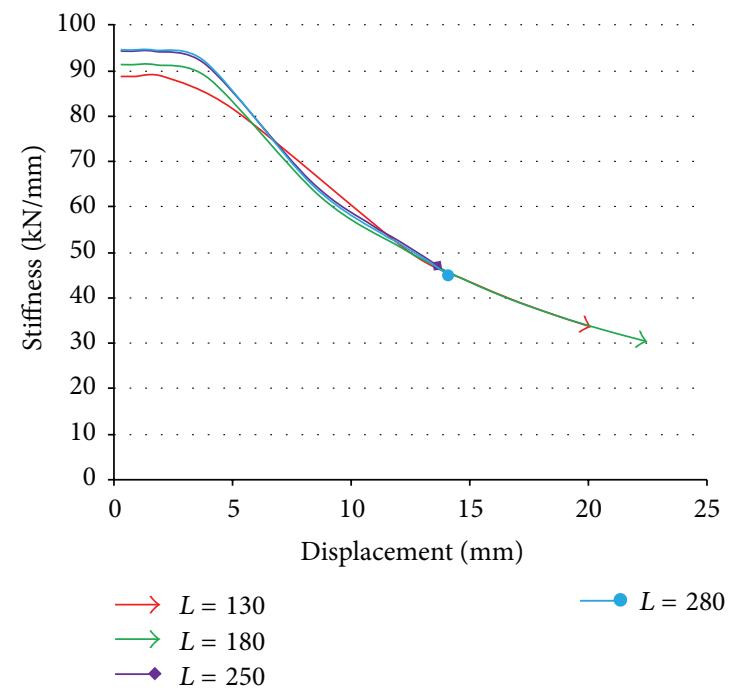

(b)

FIGURE 24: Performance of (a) load and (b) stiffness of trapezoidal corrugated plate with different corrugation lengths.

is shorter along the deformation of wall that was due to a decrease in their energy dissipation.

\section{Conclusion}

In this paper, an investigation was done on the geometrical characteristics of sinusoidal and trapezoidal corrugated onestory steel shear walls subjected to uniform lateral load, and the following results were obtained.

(1) With increasing of the corrugated plate thickness in steel shear walls, the ultimate bearing and ductility increase significantly. The obtained results of two types, namely, sinusoidal and trapezoidal corrugated plates with similar corrugation depth, showed that an increase in the thickness in sinusoidal plates caused an increase in stiffness and ultimate bearing, while this condition in the trapezoidal plate led to an increase in its ductility.

(2) Increasing the stiffness of boundary members (i.e., beam and columns) caused the ultimate bearing and ductility to be enhanced 3 to 15 percent; however, the steel wall as a whole did not change significantly. 
(3) Another parameter that is investigated in this paper is the corrugated depth. The corrugated depth was shown to be more effective on stiffness and ultimate bearing of sinusoidal plate compared to trapezoidal corrugated plates.

(4) In steel shear walls with trapezoidal corrugated plates, the walls ruptures in low thicknesses of plate are due to overall buckling, and, in medium thicknesses, this is due to local buckling in infill plate of frame, and, in high thicknesses, this is due to formation of a plastic hinge on upper beam.

(5) The corrugation density coefficient is one of the important parameters on other plates. The changes of this parameter were shown to be more effective on sinusoidal plate; increasing of these parameters caused a significant increasing process in stiffness, ductility, and ultimate bearing.

(6) An increase in corrugation length caused a decrease in the ultimate bearing and an increase in the stiffness of trapezoidal plate, but it caused no change to the stiffness of sinusoidal plate.

\section{Conflict of Interests}

The authors declare that there is no conflict of interests regarding the publication of this paper.

\section{References}

[1] M. Bruneau and T. Bhagwagar, "Seismic retrofit of flexible steel frames using thin infill panels," Engineering Structures, vol. 24, no. 4, pp. 443-453, 2002.

[2] S. Sabouri-Ghomi and M. Gholhaki, "Ductility of thin steel plate shear wall," Asian Journal of Civil Engineering, vol. 9, no. 2, pp. 153-166, 2008.

[3] A. Formisano, Seismic upgrading of existing RC buildings by means of metal shear panels: design models and full-scale tests [Thesis of doctorate], University of Napoli, 2006.

[4] A. Formisano, "Experimental-numerical investigation on stiffened pure aluminum shear panels," Pollack Periodica, vol. 1, no. 3, pp. 57-77, 2006.

[5] F. Denan, M. H. Osman, and S. Saad, "The study of lateral torsional buckling behavior of beam with trapezoid web steel section by experimental and finite element analysis," International Journal of Research and Reviews in Applied Sciences, vol. 2, no. 3, pp. 232-240, 2010.

[6] G. De Matteis, A. Formisano, S. Panico, and F. M. Mazzolani, "Numerical and experimental analysis of pure aluminium shear panels with welded stiffeners," Computers and Structures, vol. 86, no. 6, pp. 545-555, 2008.

[7] B. Stojadinovic and S. Tipping, Structural Testing of Corrugated Sheet Steel Shear Walls, University of California, Berkeley, Calif, USA, 2008.

[8] X. Wang, Behavior of steel members with trapezoidally corrugated webs and tubular flanges under static loading [Doctor of philosophy thesis], Drexel University, 2003.

[9] K. Chosa, K. Kashiwai, S. Kono, and F. Watanabe, "Fundamental study on corrugated steel webs used as shear walls," Summaries of Technical Papers of Annual Meeting Architectural Institute of Japan C, vol. 2, pp. 721-722, 2006.

[10] B. A. Irizarry, Behavior of corrugated metal panels for use as storm shutters [Doctor of philosophy thesis], University of Puerto Rico, 2009.

[11] E. Y. Sayed-Ahmed, "Design aspects of steel I-girders with corrugated steel webs," Electronic Journal of Structural Engineering, vol. 7, pp. 27-40, 2007.

[12] E. Y. Sayed-Ahmed, "Behaviour of steel and (or) composite girders with corrugated steel webs," Canadian Journal of Civil Engineering, vol. 28, no. 4, pp. 656-672, 2001.

[13] G. Kiymaz, E. Coskun, C. Cosgun, and E. Seckin, “Transverse load carrying capacity of sinusoidally corrugated steel web beams with web openings," Steel and Composite Structures, vol. 10, no. 1, pp. 69-85, 2010.

[14] Eurocode 3, Design of Steel Structures Part 1.5 Plated Structural Elements, 2003.

[15] B. Kovesdi, Patch loading resistance of girders with corrugated webs [Doctor of philosophy thesis], University of Stuttgart, Stuttgart, Germany, 2010.

[16] C. Gentilinia, L. Nobilea, and K. A. Seffenb, "Numerical analysis of morphing corrugated plates," Procedia Engineering, vol. 1, pp. 79-82, 2009.

[17] C. Gentilinia, K. A. Seffenb, S. D. Guest, and L. Nobile, "On the behavior of corrugated plates in bending," Procedia Engineering, vol. 1, pp. 79-82, 2008.

[18] Y. Tanaka, Y. Ichioka, S. Kono, Y. Ohta, and F. Watanabe, "Precast prestressed portal frames with corrugated steel panel dampers," in Proceedings of the 14th World Conference on Earthquake Engineering, Beijing, China, October 2008.

[19] R. Szilard, Theories and Applications of Plate Analysis, John Wiley \& Sons, 2004.

[20] M. Elgaaly, “Thin steel plate shear walls behavior and analysis," Thin-Walled Structures, vol. 32, no. 1-3, pp. 151-180, 1998.

[21] F. Usman, Shear Buckling of trapezoidal plate [M.S. thesis], Universiti Teknologi Malaysia, 2001.

[22] E. Y. Sayed-Ahmed, "Plate girders with corrugated steel webs," AISC Engineering Journal, vol. 42, no. 1, pp. 1-13, 2005.

[23] E. Y. Sayed-Ahmed, "Lateral stability of plate girders with corrugated steel webs," in Proceedings of the 31st Annual Conference of the Canadian Society for Civil Engineering: Building our Civilization, pp. 1244-1253, Moncton, Canada, June 2003. 

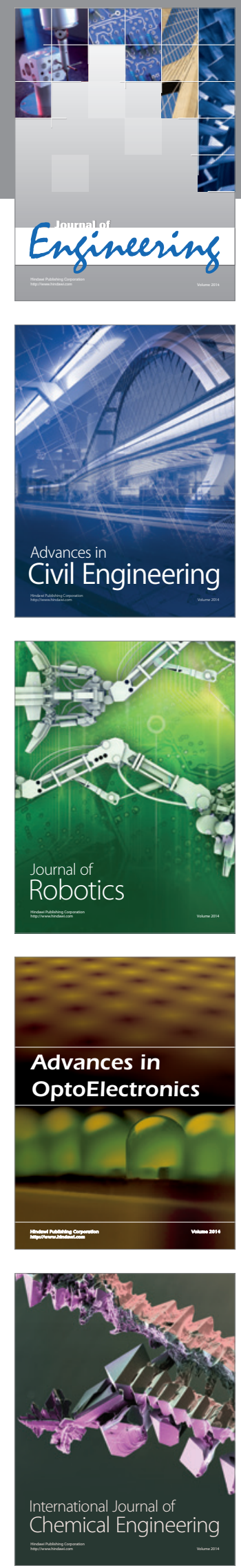

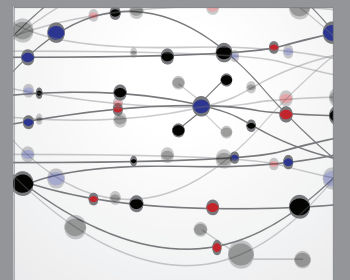

The Scientific World Journal
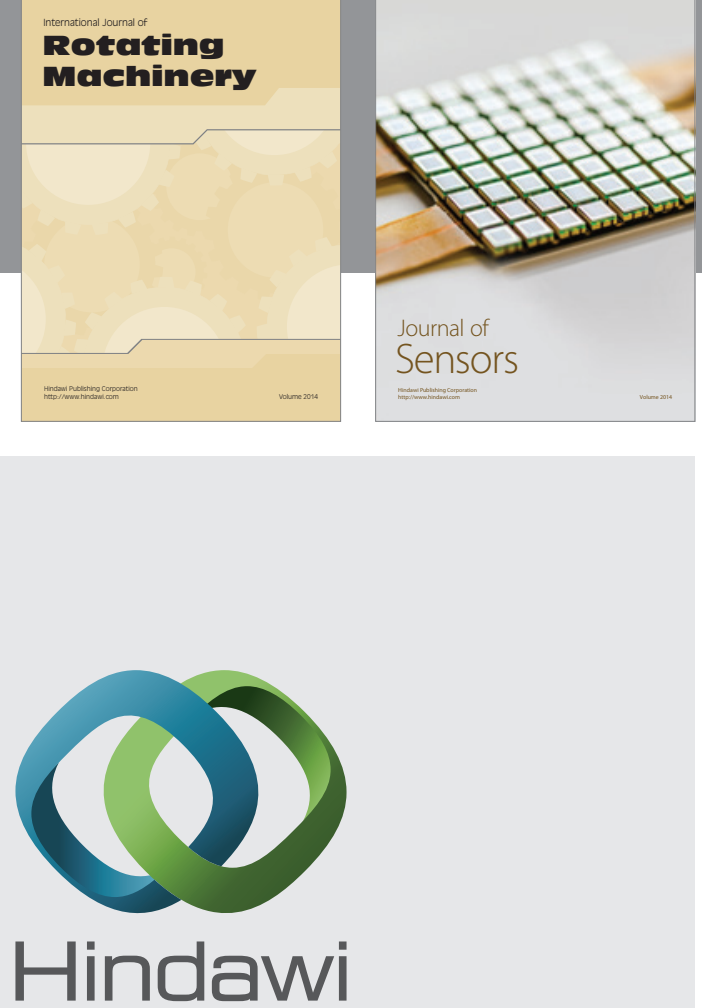

Submit your manuscripts at http://www.hindawi.com
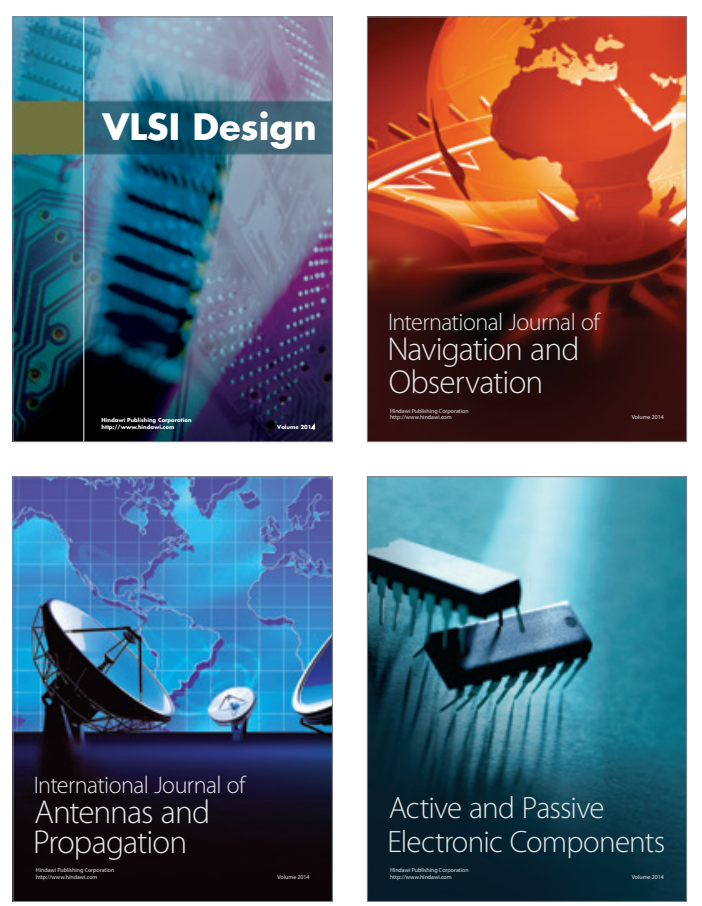
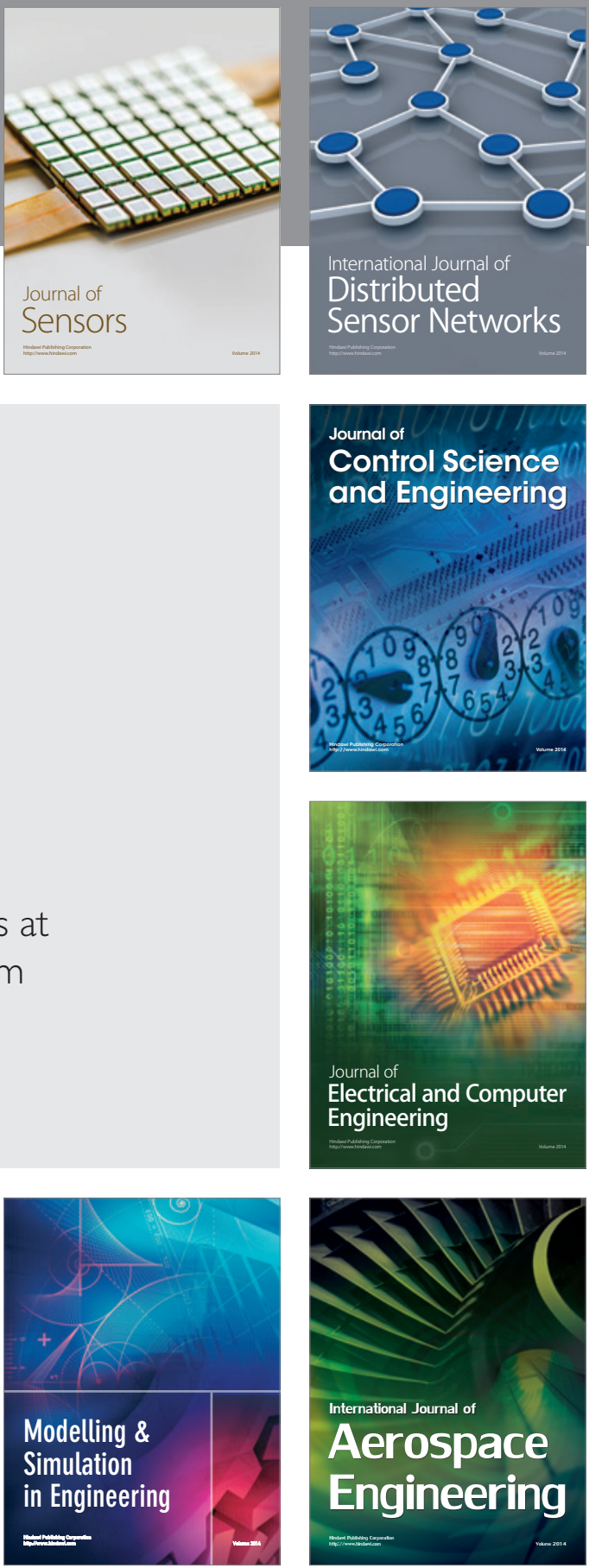

Journal of

Control Science

and Engineering
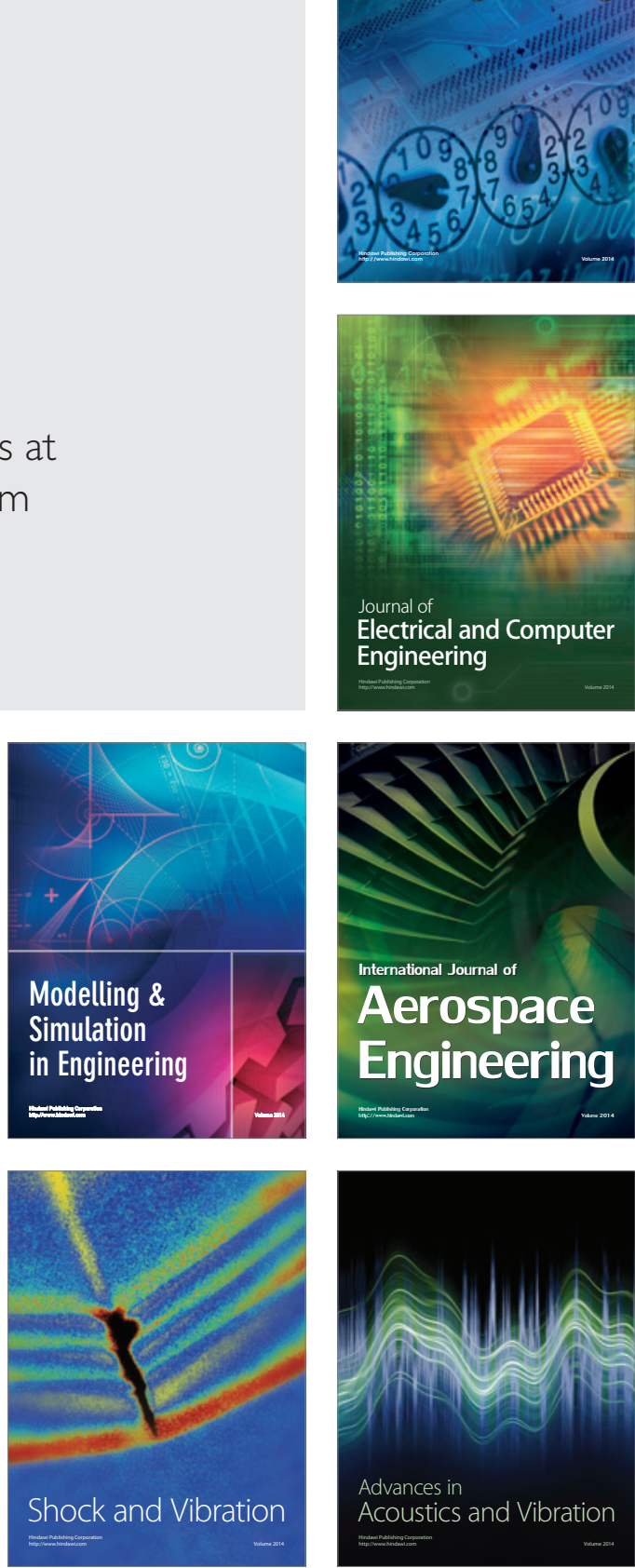